\title{
Clinical Characteristics and Outcome Trends of Adjuvant Anthracycline and Taxane Regimen for Early Stage Breast Cancer
}

\author{
Ashok K. Vaid ${ }^{\mathrm{a}, \mathrm{h}}$, Aseem Khurana ${ }^{\mathrm{b}}$, Devender Sharma ${ }^{\mathrm{c}}$, Dheeraj Gautam ${ }^{\mathrm{d}}$, Jyoti Wadhwa ${ }^{\mathrm{c}}$, \\ Rajiv Agarwale, Kanchan Kaur ${ }^{\mathrm{e}}$, Jyoti Arora ${ }^{\mathrm{f}}$, Kush Gupta ${ }^{\mathrm{g}}$
}

\begin{abstract}
Background: The anthracycline and taxane-based chemotherapy treatment regimen remains the gold standard for treatment of early stage breast cancer. However, studies examining the effectiveness and use of this treatment regimen in Indian context are limited. This study examined patients treated with anthracycline and taxane-based chemotherapy at a tertiary care cancer center in India.
\end{abstract}

Methods: Patients with confirmed early stage breast cancer who had undergone primary breast surgery followed by treatment with anthracycline and taxane-based chemotherapy between 2009 and 2015 were included in the study. Data on clinical characteristics and treatment details were collected from the patients' medical records.

Results: Two hundred sixty-four women were included in the analysis. The median age at presentation was 50 years. Among the 264 women, $40.5 \%$ were premenopausal, $1.2 \%$ were perimenopausal, and $58.3 \%$ were postmenopausal. The number of patients undergoing breast-conserving surgery (BCS) and modified radical mastectomy (MRM) were $35.2 \%$ and $64.7 \%$, respectively. Patients with a tumor grade of 1,2 , and 3 were $7.2 \%, 53.1 \%$, and $39.7 \%$, respectively. Tumors were unifocal in $81.1 \%$ and multifocal in $18.2 \%$ of patients. Estrogen receptor (ER), progesterone receptor (PR), and human epidermal growth factor receptor-2 (HER-2) positivity was detected in $58.3 \%, 54.2 \%$, and $3.1 \%$ of patients, respectively and $38.6 \%$ of pa-

Manuscript submitted April 14, 2020, accepted April 27, 2020

${ }^{a}$ Medanta Cancer Institute, Medanta-The Medicity, Gurugram, India

${ }^{b}$ Medical Oncology, Sarvodaya Multispecialty and Cancer Hospital, Hisar, India

${ }^{\mathrm{c}}$ Medical Oncology, Medanta Cancer Institute, Medanta-The Medicity, Gurugram, India

${ }^{\mathrm{d}}$ Department of Histopathology, Medanta Cancer Institute, Medanta-The Medicity, Gurugram, India

'Breast Services, Medanta Cancer Institute, Medanta-The Medicity, Gurugram, India

${ }^{f}$ Radiology and Imaging, Medanta Cancer Institute, Medanta-The Medicity, Gurugram, India

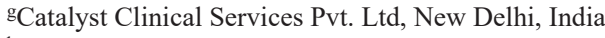

${ }^{\mathrm{h} C}$ Corresponding Author: Ashok K. Vaid, Medanta Cancer Institute, Medanta-

The Medicity, Gurugram, India. Email: akvaidonco@gmail.com

doi: https://doi.org/10.14740/wjon1284 tients were triple negative. With a median follow-up of 36.2 months, the invasive disease-free survival rate was $90.9 \%$ and mean diseasefree survival time was $65.4 \pm 1.13$ months.

Conclusions: The results of this study confirm the clinical utility of anthracycline and taxane-based chemotherapy regimen as the adjuvant chemotherapy treatment of early stage breast cancer.

Keywords: Anthracycline; Taxane; Early breast cancer; Adjuvant chemotherapy

\section{Introduction}

Breast cancer is the most common malignancy among women with over 1.67 million new cases diagnosed worldwide and 500,000 deaths reported yearly [1-3]. In a 5-year period (2008 - 2012), the incidence rate and mortality of breast cancer have increased by $20 \%$ and $14 \%$, respectively. The incidence of breast cancer is higher in developed Western regions compared to developing regions. Incidence rates also vary greatly between regions with rates as high as 89.9 per 100,000 women in Western Europe and as low as 19.3 per 100,000 women in Eastern Africa [4-6]. In India, the age adjusted incidence rate of breast cancer $(25.8$ per 100,000$)$ is low but the mortality $(12.7$ per 100,000$)$ is comparable to rates in Western regions [7-9]. Amongst Indian women, breast cancer remains the most common cancer and is the leading cause of cancer-related mortality [10].

The past few decades have witnessed a significant improvement in the survival of women with early breast cancer due to the introduction of adjuvant chemotherapy, endocrine therapy and human epidermal growth factor receptor-2 (HER-2)-directed therapies [11]. The introduction of adjuvant chemotherapy has not only decreased the risks of recurrence in early stage breast cancer, but has also improved the overall survival [12]. The anthracycline and taxane-based chemotherapy regimen is currently being used widely as a standard of care as adjuvant chemotherapeutic treatment of early stage breast cancer $[13,14]$. However, knowledge of the use and effectiveness of this treatment regimen in Indian context is limited. In this single-institution study in India, 
we aimed to understand the clinical characteristics, demographics, and outcomes of the adjuvant anthracycline and taxane-based chemotherapy regimen in routine clinical practice.

\section{Patients and Methods}

Approval of the Institutional Ethics Committee was obtained for the study. Patients included in the study adhered to the following criteria: 1) Patients with histologically or cytologically confirmed early breast cancer who underwent primary breast surgery; 2) Adjuvant treatment with anthracycline and taxanebased chemotherapy regimen; 3) Admission to the Medanta Cancer Institute between 2009 and 2015. Data on clinical characteristics and treatment details were collected from the patients' medical records.

The primary efficacy endpoint was invasive disease-free survival (IDFS). The width of the resultant confidence intervals (CIs) for parameters was constructed with a significance level of 0.05 (a 95\% CI).

Overall survival (OS) and progression-free survival (PFS) were analyzed with the use of Kaplan-Meier survival analysis, and estimates were provided with $95 \%$ CI. Statistical analysis was performed using SAS version 9.3 (SAS Institute Inc.).

\section{Results}

A total of 264 women admitted between August 2009 and July 2015 were included in the study analysis (Table 1). The median age at presentation was 50 years (range, $24-76$ years). Among the 264 women, 107 (40.5\%) were premenopausal, three (1.2\%) were perimenopausal, and 154 (58.3\%) were postmenopausal. The number of patients undergoing breast-conserving surgery (BCS) and modified radical mastectomy (MRM) were $35.2 \%$ and $64.7 \%$, respectively. Estrogen receptor (ER), progesterone receptor (PR) and HER-2 receptor positivity was detected in $58.3 \%, 54.2 \%$ and $3.1 \%$ of patients, respectively and $38.6 \%$ of patients were triple negative. Although the overall HER-2 receptor positivity at our center is $25.2 \%$, the subset of HER-2 receptor positive patients treated according to the anthracycline and taxanebased chemotherapy regimen represented $3.1 \%$ of our focused study population.

As a part of the study, we tracked the recurrence status of the breast cancer patients (Table 2). With a median follow-up time of 36.2 months (range, 0.2 - 98.7 months), 24 (9.1\%) patients experienced recurrence of disease whereas $240(90.9 \%)$ were disease-free. Since, there was an unequal distribution of events and censoring, median IDFS duration could not be estimated (Fig. 1). However, the mean disease-free survival duration was found to be $65.4 \pm 1.13$ months. The association of each of the individual factor with regards to disease recurrence and disease-free survival are presented in Tables 3 and 4 , respectively. While the number of positive nodes was significantly associated with recurrence of disease $(\mathrm{P}<0.05)$, as well as disease-free survival $(\mathrm{P}<0.05)$; there was a decreased
Table 1. Summary of Patient Demographic and Clinical Characteristics

\begin{tabular}{|c|c|}
\hline & Total, $n(\%)(n=264)$ \\
\hline \multicolumn{2}{|l|}{ Age, years } \\
\hline$<35$ & $23(8.7 \%)$ \\
\hline $35-50$ & $111(42.1 \%)$ \\
\hline$>50$ & $130(49.2 \%)$ \\
\hline Median age, years (range) & $50(24-76)$ \\
\hline \multicolumn{2}{|l|}{ Gender } \\
\hline Female & $262(99.2 \%)$ \\
\hline Male & $2(0.8 \%)$ \\
\hline \multicolumn{2}{|l|}{ Menopausal status } \\
\hline Premenopause & $107(40.5 \%)$ \\
\hline Perimenopause & $3(1.2 \%)$ \\
\hline Postmenopause & $154(58.3 \%)$ \\
\hline \multicolumn{2}{|l|}{ Breast laterality } \\
\hline Left & $144(54.6 \%)$ \\
\hline Right & $116(43.9 \%)$ \\
\hline Bilateral & $4(1.5 \%)$ \\
\hline \multicolumn{2}{|l|}{ Type of surgery } \\
\hline BCS & $93(35.2 \%)$ \\
\hline MRM & $171(64.8 \%)$ \\
\hline \multicolumn{2}{|l|}{ Tumor grade } \\
\hline 3 & $105(39.7 \%)$ \\
\hline 2 & $140(53.1 \%)$ \\
\hline 1 & $19(7.2 \%)$ \\
\hline \multicolumn{2}{|l|}{ Margin } \\
\hline Free & $262(99.2 \%)$ \\
\hline Involved & $2(0.8 \%)$ \\
\hline \multicolumn{2}{|l|}{ Histology } \\
\hline Circumscribed & $16(6.1 \%)$ \\
\hline Infiltrative & $243(92.1 \%)$ \\
\hline Pushing & $4(1.5 \%)$ \\
\hline Missing & $1(0.3 \%)$ \\
\hline \multicolumn{2}{|l|}{ Tumor focality } \\
\hline Single & $214(81.1 \%)$ \\
\hline Multifocal & $48(18.2 \%)$ \\
\hline Unknown & $2(0.7 \%)$ \\
\hline \multicolumn{2}{|l|}{ Involvement of skin } \\
\hline Yes & $10(3.8 \%)$ \\
\hline No & $251(95.1 \%)$ \\
\hline Free & $3(1.1 \%)$ \\
\hline \multicolumn{2}{|l|}{ DCIS } \\
\hline Yes & $137(51.9 \%)$ \\
\hline
\end{tabular}


Table 1. Summary of Patient Demographic and Clinical Characteristics - (continued)

\begin{tabular}{|c|c|}
\hline & Total, n $(\%)(n=264)$ \\
\hline No & $125(47.4 \%)$ \\
\hline Unknown & $2(0.7 \%)$ \\
\hline \multicolumn{2}{|l|}{ Lymphovascular invasion } \\
\hline Yes & $153(57.9 \%)$ \\
\hline No & $100(37.9 \%)$ \\
\hline Intermediate & $1(0.4 \%)$ \\
\hline Indeterminate & $8(3.1 \%)$ \\
\hline Unknown & $2(0.7 \%)$ \\
\hline $\begin{array}{l}\text { Median number of nodes } \\
\text { dissected (range) }\end{array}$ & $17(1-74)$ \\
\hline \multicolumn{2}{|l|}{ Node positive } \\
\hline Yes & $191(72.3 \%)$ \\
\hline 1 - 4 nodes & $131(49.6 \%)$ \\
\hline$>4$ nodes & $60(22.7 \%)$ \\
\hline No & $73(27.7 \%)$ \\
\hline \multicolumn{2}{|l|}{ Hormonal status } \\
\hline $\mathrm{ER}+$ & $154(58.3 \%)$ \\
\hline $\mathrm{PR}+$ & $143(54.2 \%)$ \\
\hline HER + & $8(3.1 \%)$ \\
\hline $\mathrm{ER}+, \mathrm{PR}+, \mathrm{HER}-$ & $134(50.7 \%)$ \\
\hline $\mathrm{ER}+, \mathrm{PR}+, \mathrm{HER}+$ & $4(1.5 \%)$ \\
\hline ER-, PR-, HER- (TNBC) & $102(38.6 \%)$ \\
\hline \multicolumn{2}{|l|}{ Treatment details } \\
\hline \multicolumn{2}{|l|}{ Chemotherapy } \\
\hline Yes & $264(100 \%)$ \\
\hline \multicolumn{2}{|l|}{ Hormonal therapy } \\
\hline Yes & $169(64 \%)$ \\
\hline No & $95(36 \%)$ \\
\hline \multicolumn{2}{|l|}{ Radiotherapy } \\
\hline Yes & $202(76.5 \%)$ \\
\hline No & $62(23.5 \%)$ \\
\hline \multicolumn{2}{|l|}{ Supportive treatment } \\
\hline G-CSF & $50(18.9 \%)$ \\
\hline Peg-G-CSF & $120(45.5 \%)$ \\
\hline Both & $63(23.9 \%)$ \\
\hline None & $31(11.7 \%)$ \\
\hline $\begin{array}{l}\text { Duration of follow-up } \\
\text { (months), median (range) }\end{array}$ & $36.2(0.2$ to 98.7$)$ \\
\hline
\end{tabular}

BCS: breast-conserving surgery; MRM: modified radical mastectomy; DCIS: ductal carcinoma in situ; G-CSF: granulocyte-colony stimulating factor; Peg-G-CSF: pegylated-G-CSF; ER: estrogen receptor; PR: progesterone receptor; HER-2: human epidermal growth factor receptor-2.
Table 2. Recurrence Status of Patients

\begin{tabular}{ll}
\hline Recurrence & Total, $\mathbf{n}(\mathbf{\%})(\mathbf{n}=\mathbf{2 6 4})$ \\
\hline Yes & $24(9.1 \%)$ \\
No & $240(90.9 \%)$ \\
\hline
\end{tabular}

association of breast laterality with recurrence of disease $(\mathrm{P}=$ 0.06 ). While some common grade $1 / 2$ toxicities were observed in our study population (Table 5), none of the patient experienced any grade $3 / 4$ toxicities due to the usage of supportive care with granulocyte-colony stimulating factor (G-CSF) and pegylated-G-CSF.

\section{Discussion}

Chemotherapeutic treatment with anthracyclines (e.g., doxorubicin, epirubicin, liposomal doxorubicin) and taxanes (e.g., docetaxel, paclitaxel, nab-paclitaxel) have shown superiority over the previously used cyclophosphamide, methotrexate and fluorouracil (CMF) combination therapy. Therefore, this treatment strategy is now considered the gold standard for adjuvant chemotherapeutic treatment of early stage breast cancer [1319]. In an attempt to strengthen the evidence regarding the efficacy of anthracycline and taxane-based treatment, besides the present study, a number of clinical trials have been conducted to evaluate the best agent, dose, and sequence of administration for the treatment of breast cancer [20-24].

In a retrospective study of 1,600 patients, Alvarez et al examined the usual adjuvant sequence of anthracycline followed by taxane and showed a significant higher risk of death compared to the reverse sequence (taxane followed by anthracycline) [25]. Another study reviewed 15 previous studies with a total of nearly 5,000 breast cancer patients treated with anthracyclines and taxanes in an adjuvant or neoadjuvant setting. Their work concluded that taxane followed by anthracycline could be incorporated into routine clinical practice [26].

The adjuvant sequence of anthracycline followed by taxane used in our study is consistent with that followed in previously published reports. The American Society of Clinical Oncology guideline adaptation of the Cancer Care Ontario Clinical Practice guidelines recommends the use of a regimen containing anthracycline and taxane as an optimal adjuvant chemotherapy strategy for patients who are deemed to be at high risk [27]. A 15-year meta-analysis comprising 100,000 women treated across 123 randomized trials demonstrated a reduction in 10-year breast cancer mortality by one-third with anthracycline-based chemotherapy regimens as compared to no chemotherapy [13]. However, anthracycline regimens were associated with increased risk of cardiac mortality, myelodysplastic syndromes and treatment-related leukemia [13, 22]. A series of three randomized adjuvant trials (The ABC TriasUS Oncology Research (USOR) 06-090, National Surgical Adjuvant Breast and Bowel Project (NSABP) B-46-I/USOR 07132 and NSABP B-49 (NRG Oncology)) evaluated the role of anthracyclines in early breast cancer [28]. However, in that 


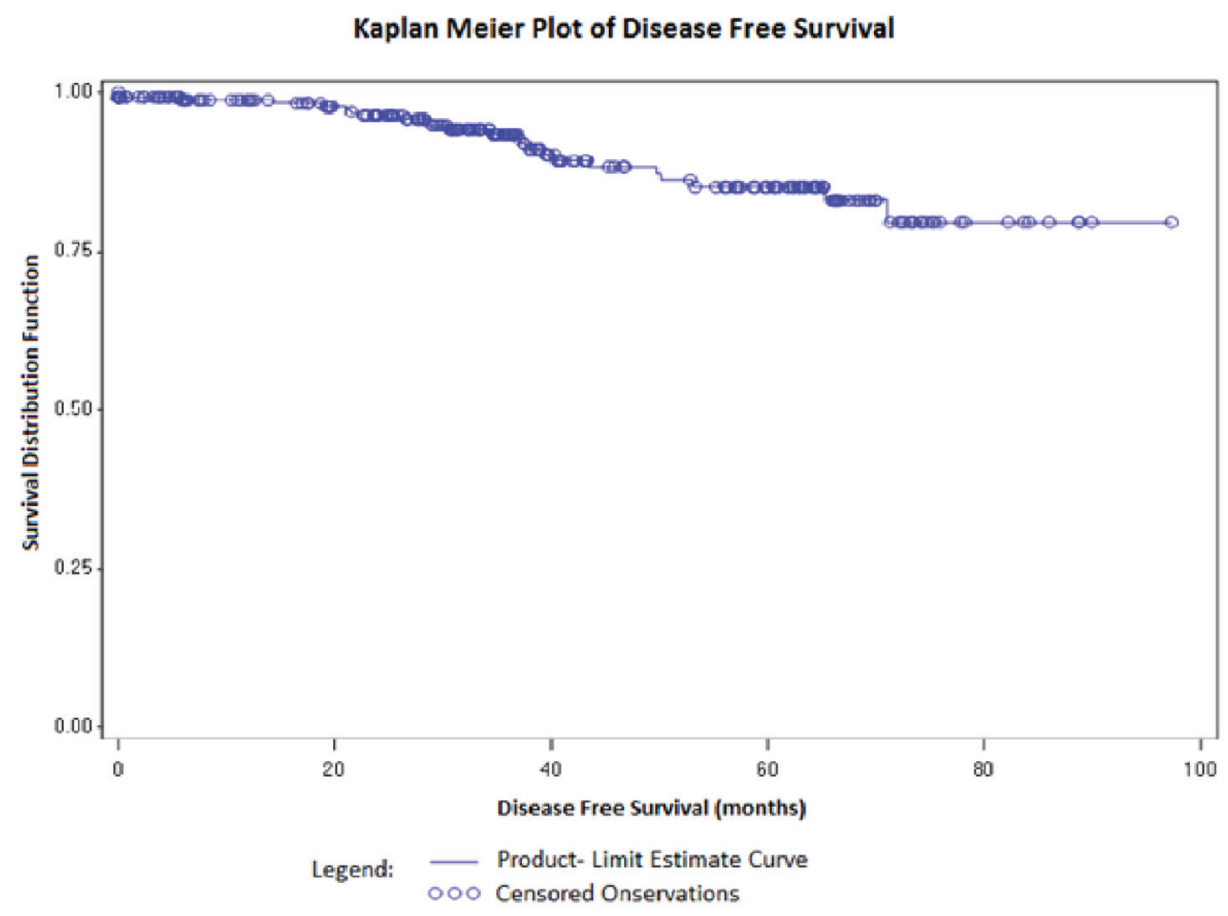

Figure 1. Kaplan-Meier survival analysis for invasive disease-free survival (IDFS).

series of trials, fewer patients were under the age of 50 years, compared with our study population. This discrepancy could be due to the prevalence of early breast cancer in younger age groups in India compared to Western regions. Additionally, these studies showed a decreased frequency of $\geq 10$ positive nodes in the tumors suggesting that more aggressive disease may strike Indian women compared to their Western counterparts.

While the USOR 06-090 study compared six cycles of docetaxel and cyclophosphamide (TC6) with docetaxel, doxorubicin and cyclophosphamide (TAC6), the NSABP B-46-I/ USOR 07132 study compared TC6, TAC6 or TC6 plus bevacizumab. On the other hand, the NSABP B-49 study compared TC6 with several standard doxorubicin and cyclophosphamide (AC) with taxanes combination regimens (TaxAC). With a median follow-up of 36.2 months and an IDFS of $90.9 \%$, our study is consistent with findings reported in the NSABP B-49 study.

The Early Breast Cancer Trialists' Collaborative Group (EBCTCG) conducted a meta-analysis of 10 randomized trials to investigate the long-term outcome for neoadjuvant versus adjuvant chemotherapy in early breast cancer [29]. There was more frequent 15-year local recurrence with neoadjuvant chemotherapy as compared to adjuvant chemotherapy in this study. However, no difference was noted between the two groups for distal tumor recurrence or death. Although, the mean disease-free survival duration of $65.4 \pm 1.13$ months achieved in our study has not reached the milestone of 10 to 15 years, the results are encouraging with regards to the clinical advantage of adjuvant anthracycline and taxane-based chemotherapy of early stage breast cancer. The results of our study demonstrate the clinical utility of adjuvant anthracycline and taxane-based chemotherapy regimen in early stage breast cancer during the routine clinical practice.

Table 3. Cox Regression Analysis for Recurrence of Disease

\begin{tabular}{llll}
\hline Effect & Degree of freedom & Wald Chi-square & Pvalue \\
\hline Breast laterality & 2 & 5.50 & 0.06 \\
Number of positive nodes & 1 & 5.42 & 0.02 \\
Grade of tumor & 2 & 3.26 & 0.19 \\
\hline
\end{tabular}

Table 4. Cox Regression Analysis for Disease-Free Survival

\begin{tabular}{llll}
\hline Effect & Degree of freedom & Wald Chi-square & P value \\
\hline Breast laterality & 2 & 3.84 & 0.15 \\
Number of positive nodes & 1 & 3.58 & 0.05 \\
\hline
\end{tabular}


Table 5. Common Grade 1/2 Toxicities

\begin{tabular}{ll}
\hline Toxicity & Total, $\mathbf{n}(\mathbf{\%})(\mathbf{n}=\mathbf{2 6 4})$ \\
\hline Cough & $6(2.3 \%)$ \\
Desquamation & $9(3.4 \%)$ \\
Dysphagia & $7(2.7 \%)$ \\
Erythema & $31(11.7 \%)$ \\
Fatigue & $4(1.5 \%)$ \\
Fever & $4(1.5 \%)$ \\
Generalized pain & $13(4.9 \%)$ \\
Hyperpigmentation & $18(6.8 \%)$ \\
Itching & $3(1.1 \%)$ \\
Loss of appetite & $2(0.8 \%)$ \\
Maculopapular rash & $10(3.8 \%)$ \\
Nausea & $8(3 \%)$ \\
Odynophagia & $6(2.3 \%)$ \\
Vomiting & $4(1.5 \%)$ \\
\hline
\end{tabular}

\section{Clinical practice points}

Clinical practice points included: 1) Anthracycline and taxanebased chemotherapies are the standard of care for breast cancer treatment; 2) This is the first study examining the effects of anthracycline and taxane-based chemotherapeutic treatment of Indian breast cancer patients; 3) The average age at time of diagnosis for early breast cancer patients was 50 years; 4) With a median follow-up time of 36.2 months, $9.1 \%$ of patients had recurrence of disease and the remaining $90.9 \%$ were diseasefree; 5) The mean disease-free survival time was $65.4 \pm 1.13$ months; 6) While a portion of the patients experienced grade $1 / 2$ toxicities, none of the population experienced grade $3 / 4$ toxicities due to supportive care with G-CSF based interventions.

\section{Conclusions}

Our study is the first Indian cohort focused analysis of the impact of anthracycline and taxane-based adjuvant chemotherapy regimen in the treatment of early stage breast cancer. Further follow-up research will need to be conducted to assess the long-term utility of this treatment regimen. Additionally, analysis of the treatments in the context of a prospective study on the treatment regimen should be conducted. Although our retrospective study has limitations, it confirms the clinical utility of anthracycline and taxane-based chemotherapy regimen in the adjuvant chemotherapy treatment of early stage breast cancer.

\section{Acknowledgments}

None to declare.

\section{Financial Disclosure}

The author received no financial support for the research, authorship, and/or publication of this article.

\section{Conflict of Interest}

The author declared no potential conflict of interest with respect to the research, authorship, and/or publication of this article.

\section{Informed Consent}

This study was reviewed by the Institutional Review Board and was exempted from the requirement for informed consent.

\section{Author Contributions}

Ashok K. Vaid was responsible for the conception and design of this paper, acquisition of data, analysis and interpretation of data, drafting the article and final approval of the version to be published. Aseem Khurana and Devender Sharma were responsible for the acquisition of data and final approval of the version to be published. Dheeraj Gautam, Jyoti Wadhwa, Rajiv Agarwal, Kanchan Kaur, Jyoti Arora and Kush Gupta were responsible for drafting the article and final approval of the version to be published.

\section{Data Availability}

The authors declare that data supporting the findings of this study are available within the article.

\section{References}

1. Ferlay J, Soerjomataram I, Dikshit R, Eser S, Mathers C, Rebelo M, Parkin DM, et al. Cancer incidence and mortality worldwide: sources, methods and major patterns in GLOBOCAN 2012. Int J Cancer. 2015;136(5):E359-386.

2. Ferlay J, Steliarova-Foucher E, Lortet-Tieulent J, Rosso S, Coebergh JW, Comber H, Forman D, et al. Cancer incidence and mortality patterns in Europe: estimates for 40 countries in 2012. Eur J Cancer. 2013;49(6):1374-1403.

3. de Martel C, Ferlay J, Franceschi S, Vignat J, Bray F, Forman D, Plummer M. Global burden of cancers attributable to infections in 2008: a review and synthetic analysis. Lancet Oncol. 2012;13(6):607-615.

4. Launoy G. Epidemiology of cancers in France. Rev Prat. 2010;60(2):178-182.

5. Jung KW, Won YJ, Park S, Kong HJ, Sung J, Shin HR, Park EC, et al. Cancer statistics in Korea: incidence, mortality and survival in 2005. J Korean Med Sci. 2009;24(6):995-1003. 
6. Hery C, Ferlay J, Boniol M, Autier P. Quantification of changes in breast cancer incidence and mortality since 1990 in 35 countries with Caucasian-majority populations. Ann Oncol. 2008;19(6):1187-1194.

7. Gupta A, Shridhar K, Dhillon PK. A review of breast cancer awareness among women in India: Cancer literate or awareness deficit? Eur J Cancer. 2015;51(14):2058-2066.

8. Sharma K, Costas A, Shulman LN, Meara JG. A systematic review of barriers to breast cancer care in developing countries resulting in delayed patient presentation. J Oncol. 2012;2012:121873.

9. Jones CE, Maben J, Jack RH, Davies EA, Forbes LJ, Lucas G, Ream E. A systematic review of barriers to early presentation and diagnosis with breast cancer among black women. BMJ Open. 2014;4(2):e004076.

10. Kaarthigeyan K. Cervical cancer in India and HPV vaccination. Indian J Med Paediatr Oncol. 2012;33(1):7-12.

11. Cossetti RJ, Tyldesley SK, Speers CH, Zheng Y, Gelmon KA. Comparison of breast cancer recurrence and outcome patterns between patients treated from 1986 to 1992 and from 2004 to 2008. J Clin Oncol. 2015;33(1):65-73.

12. Systemic treatment of early breast cancer by hormonal, cytotoxic, or immune therapy. 133 randomised trials involving 31,000 recurrences and 24,000 deaths among 75,000 women. Early Breast Cancer Trialists' Collaborative Group. Lancet. 1992;339(8785):71-85.

13. Early Breast Cancer Trialists' Collaborative Group, Peto R, Davies C, Godwin J, Gray R, Pan HC, Clarke M, et al. Comparisons between different polychemotherapy regimens for early breast cancer: meta-analyses of long-term outcome among 100,000 women in 123 randomised trials. Lancet. 2012;379(9814):432-444.

14. Early Breast Cancer Trialists' Collaborative Group. Effects of chemotherapy and hormonal therapy for early breast cancer on recurrence and 15-year survival: an overview of the randomised trials. Lancet. 2005;365(9472):1687-1717.

15. Wildiers H, Forceville K, Paridaens R, Joensuu H. Taxanes and anthracyclines in early breast cancer: which first? Lancet Oncol. 2010;11(3):219-220.

16. Puhalla S, Mrozek E, Young D, Ottman S, McVey A, Kendra K, Merriman NJ, et al. Randomized phase II adjuvant trial of dose-dense docetaxel before or after doxorubicin plus cyclophosphamide in axillary node-positive breast cancer. J Clin Oncol. 2008;26(10):1691-1697.

17. Piedbois P, Serin D, Priou F, Laplaige P, Greget S, Angellier E, Teissier E, et al. Dose-dense adjuvant chemotherapy in node-positive breast cancer: docetaxel followed by epirubicin/cyclophosphamide (T/EC), or the reverse sequence $(\mathrm{EC} / \mathrm{T})$, every 2 weeks, versus docetaxel, epirubicin and cyclophosphamide (TEC) every 3 weeks. AERO B03 randomized phase II study. Ann Oncol. 2007;18(1):52-57.

18. Levine MN, Pritchard KI, Bramwell VH, Shepherd LE, Tu D, Paul N, National Cancer Institute of Canada Clinical Trials Group. Randomized trial comparing cyclophosphamide, epirubicin, and fluorouracil with cyclophosphamide, methotrexate, and fluorouracil in premenopausal women with node-positive breast cancer: update of $\mathrm{Na}$ tional Cancer Institute of Canada Clinical Trials Group Trial MA5. J Clin Oncol. 2005;23(22):5166-5170.
19. Poole CJ, Earl HM, Hiller L, Dunn JA, Bathers S, Grieve RJ, Spooner DA, et al. Epirubicin and cyclophosphamide, methotrexate, and fluorouracil as adjuvant therapy for early breast cancer. N Engl J Med. 2006;355(18):1851-1862.

20. Sparano JA, Wang M, Martino S, Jones V, Perez EA, Saphner T, Wolff AC, et al. Weekly paclitaxel in the adjuvant treatment of breast cancer. N Engl J Med. 2008;358(16):1663-1671.

21. Wood WC, Budman DR, Korzun AH, Cooper MR, Younger J, Hart RD, Moore A, et al. Dose and dose intensity of adjuvant chemotherapy for stage II, node-positive breast carcinoma. N Engl J Med. 1994;330(18):1253-1259.

22. Henderson IC, Berry DA, Demetri GD, Cirrincione CT, Goldstein LJ, Martino S, Ingle JN, et al. Improved outcomes from adding sequential Paclitaxel but not from escalating Doxorubicin dose in an adjuvant chemotherapy regimen for patients with node-positive primary breast cancer. J Clin Oncol. 2003;21(6):976-983.

23. Citron ML, Berry DA, Cirrincione C, Hudis C, Winer EP, Gradishar WJ, Davidson NE, et al. Randomized trial of dose-dense versus conventionally scheduled and sequential versus concurrent combination chemotherapy as postoperative adjuvant treatment of node-positive primary breast cancer: first report of Intergroup Trial C9741/ Cancer and Leukemia Group B Trial 9741. J Clin Oncol. 2003;21(8):1431-1439.

24. Swain SM, Jeong JH, Geyer CE, Jr., Costantino JP, Pajon ER, Fehrenbacher L, Atkins JN, et al. Longer therapy, iatrogenic amenorrhea, and survival in early breast cancer. N Engl J Med. 2010;362(22):2053-2065.

25. Alvarez RH, Bianchini G, Hsu L, Cristofanilli M, Esteva FJ, Pusztai L, Buzdar AU, et al. Clinical outcome of two sequences of administering paclitaxel (P) and anthracyclines (A) as primary systemic therapy (PST) and adjuvant chemotherapy (ACT) in breast cancer (BC) patients: a retrospective analysis from the M. D. Anderson Cancer Center (MDACC). Cancer Res. 2010;70(24 Suppl):P5-10-02.

26. Bines J, Earl H, Buzaid AC, Saad ED. Anthracyclines and taxanes in the neo/adjuvant treatment of breast cancer: does the sequence matter? Ann Oncol. 2014;25(6):1079-1085.

27. Denduluri N, Somerfield MR, Eisen A, Holloway JN, Hurria A, King TA, Lyman GH, et al. Selection of optimal adjuvant chemotherapy regimens for human epidermal growth factor receptor 2 (HER2) -negative and adjuvant targeted therapy for HER2-positive breast cancers: an American society of clinical oncology guideline adaptation of the cancer care ontario clinical practice guideline. J Clin Oncol. 2016;34(20):2416-2427.

28. Blum JL, Flynn PJ, Yothers G, Asmar L, Geyer CE, Jr., Jacobs SA, Robert NJ, et al. Anthracyclines in early breast cancer: the ABC trials-USOR 06-090, NSABP B46-I/USOR 07132, and NSABP B-49 (NRG Oncology). J Clin Oncol. 2017;35(23):2647-2655.

29. Early Breast Cancer Trialists' Collaborative Group. Longterm outcomes for neoadjuvant versus adjuvant chemotherapy in early breast cancer: meta-analysis of individual patient data from ten randomised trials. Lancet Oncol. 2018;19(1):27-39. 